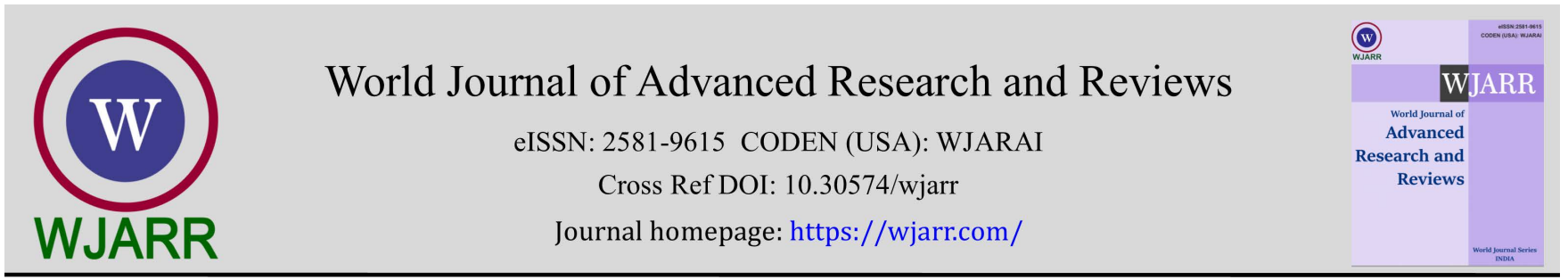

(RESEARCH ARTiClE)

Check for updates

\title{
Piper nigrum based diet had a chemopreventive antineoplastic effect potentiated by Curcuma longa in C57BL/6 mice
}

Pérez-Pérez Ana Isabel, Quiroz-Guerra Kimberly Alexandra, Ruiz-Escalona Evelyn Victoria and BonfanteCabarcas Rafael Armando*

Young Scientic Talent Program, Biochemistry Research Unit, Health Science School, Universidad Centroccidental Lisandro Alvarado, Av Libertador/Andres Bello, PC: 3001, Barquisimeto, Venezuela.

World Journal of Advanced Research and Reviews, 2021, 09(03), 188-203

Publication history: Received on 04 February 2021; revised on 06 March 2021; accepted on 09 March 2021

Article DOI: https://doi.org/10.30574/wjarr.2021.9.3.0088

\begin{abstract}
Background: Medicinal plants represent a proven alternative strategy to treat cancer.

Objective: To determine Curcuma longa (turmeric) and Piper nigrum (black pepper) effects in vitro and on the evolution of malignant melanoma B16F10 in C57BL/6 mice.

Methods: 103 female mice divided in 4 groups: Control $(n=44)$, Turmeric $(n=20)$, Pepper $(n=21)$, Turpepp (n=18). Turmeric $5 \%$ and/or pepper $0.5 \%$ were mixed with a dough made of pre-cooked cornmeal, eggs and coconut milkshake and given ad libitum to experimental groups as main diet; control received dough based diet. 200,000 melanoma cells were transplanted into right leg hind paw. Clinical, psychological, pathological and biochemical parameters were evaluated in vivo to measure melanoma progression. In vitro, metabolic activity was measured by quantifying anaerobic glycolysis and viability through MTT assay.
\end{abstract}

Results: Combined preventive treatment with turmeric and pepper increased latency time for tumor onset, improved locomotor activity, preserved nociceptive response, decreased tumor volume and weight, reduced metastases and increased survival. These results were reproduced in the Pepper group, but with less statistical force; however, pepper showed greater potency in vitro experiments.

Conclusion: Pepper showed an antineoplastic chemopreventive activity in B16F10 malignant melanoma, which was enhanced by the synergistic effect of turmeric.

Keywords: Curcuma long; Piper nigrum; B16F10 Malignant Melanoma; cancer; C57BL/6 mice; scientific talent

\section{Introduction}

Cancer starts with accumulated genetic mutations that allow malignant transformation of a natural cell, characterized by increased and unceasingly proliferation, acquiring invasion and colonization capacity that causes metastasis [1].

Cancer is the second leading cause of mortality after cardiovascular diseases, being a disappointed public health problem around the world, with an incidence of 14 and mortality of 8 million people (WHO, 2014); mortality caused by cancers will increase, it is predicted by 2030 more than 13.1 million deaths will occur worldwide [2].

\footnotetext{
* Corresponding author: Rafael Armando Bonfante-Cabarcas

Young Scientic Talent Program, Biochemistry Research Unit, Health Science School, Universidad Centroccidental Lisandro Alvarado, Av Libertador/Andres Bello, PC: 3001, Barquisimeto, Venezuela.

Copyright (C) 2021 Author(s) retain the copyright of this article. This article is published under the terms of the Creative Commons Attribution Liscense 4.0.
} 
Melanoma is a melanocyte malignant skin cancer, which has an elevated metastasis rate. By 2012, WHO estimated an incidence of 232,000 people and mortality of 55.000 people, caused by malignant melanoma and other skin cancer [2].

The protocol used to treat melanoma depends on the evolution of the disease. During 0 , I and II stages, treatment is based on surgery, including tumorectomy and extraction of metastatic satellites ganglia. In III and IV stages, treatment comprise surgery, chemo, radio and/or immunotherapies. In invasive stages (IV stage), prognosis is worst, with a 10 to $15 \%$ survival rate in 10 years, having treatment poor response [1]. It should be underlined, that the most negative issue about cancer treatment, based on chemotherapy and radiotherapy, is the fact that these protocols are not selective, causing a high percentage of healthy cells lost, together with cancer cells. For this reason, it is desirable to look for supplementary preventive and/or therapeutic protocols, with the aim to prevent disease development, to favor a benign evolution of the tumor, to improve curative and survival rates, and especially to preserve the quality of life.

Herbaria medicine has been used from remotes times to treat a variety of human diseases, given up to phytopharmaceuticals; $25 \%$ of the drugs usually used to treat cancer derive from medicinal plants. The beneficial effects of medicinal plants in cancer treatment have been studied with encouraging results [3]. Therefore, development and availability of natural products, with higher effectiveness against cancer cells and lower side effects would be desired.

Phenolic compounds derived from medicinal plants are promising substances to prevent and treat cancer. Anticancer efficacy of major polyphenol classes like flavonoids, phenolic acids, lignans and stilbenes are based on mechanisms including antioxidant and anti-inflammation, as well as the modulation of multiple molecular events involved in carcinogenesis [4].

Curcuma longa (turmeric) is a medicinal plant from the Zingiberaceae family. Its main habitat is hot areas in Asia, for example India, Pakistan, Indonesia, and southern China, and it is native in Africa and South America. Turmeric has been widely used for its anti-oxidant, antiseptic, analgesic, antimalarial and anti-inflammatory properties. Turmeric contains curcuminoids, phenolic compounds that include curcumin, demethoxycurcumin and bisdemethoxycurcumin. Curcumin is responsible for the yellow color of the spice, as well as for the majority of turmeric's therapeutic effects. Turmeric has been consumed as a dietary supplement for centuries, being considered pharmacologically safe [5].

Curcumin has been studied in multiple human carcinomas, including melanoma. It targets various transcription factors, oncogenes and signaling proteins, affecting in these way, many levels of regulation at various temporal stages of carcinogenesis; from the initial insults leading to DNA mutations, through the process of tumorigenesis, growth and metastasis; in addition, it can induce apoptosis [6]. These characteristics define it as a chemopreventive and curative agent.

Piper nigrum (black pepper) belongs to the Piperaceae family; it is the most commonly used and highly appraised spice in the world. It has numerous pharmacological activities like antihypertensive, antiasthmatic, antimicrobial, antioxidant, anticancer, anti-inflammatory, and immunomodulatory activities. Several phytochemicals have been isolated from black pepper, among these phenolic acids are considered responsible for its preventive and medicinal activities [7].

Piperine is an alkaloid extracted from Piper nigrum, which exhibits a variety of biological activities, including antipyretic, anti-inflammatory, anti-depressant, hepatoprotective and antitumor activities. It has been reported that piperine is able to decrease proliferation and to increase apoptosis of cancer cells, representing a compound with preventive and curative properties against cancer. In addition, piperine sensitize breast (including triple negative), colon and prostate cancer cells to chemotherapy and radiation. While, in murine as well as in human melanoma cells, piperine had antiproliferative activity, trough ROS generation-induced Chk1 activation, causing G1 cell cycle arrest and apoptosis $[8,9]$.

Piperine has also been known to inhibit CYP3A4 and P-glycoprotein, due to which it has been used to enhance the bioavailability of other drugs [10]. When co-administered with curcumin, piperine increased the bioavailability of curcumin by $2000 \%$ [11], however, nevertheless curcumin has this property, and no studies had ever evaluated the effect of therapeutic combination of pepper with turmeric compounds in the treatment of melanoma.

For that reason, in the present paper we have studied the effect of Curcuma longa and Piper nigrum on the evolution of the B16F10 malignant melanoma in $\mathrm{C57Bl} / 6$ mice, with the aim to prove theirs synergistic, chemopreventive and antineoplastic properties against malignant melanoma. 


\section{Material and methods}

\subsection{Population and sample}

It was constituted by 103 female $\mathrm{C} 57 \mathrm{Bl} / 6$ mice, with an average weight of $18.86 \pm 0.65$ gr, divided into 4 groups called: Control $(n=44)$, Turmeric $(n=20)$, Pepper $(n=21)$, Turpepp $(n=18)$. Animals were provided by animal facilities at the Universidad Centrocidental "Lisandro Alvarado", (Barquisimeto, Venezuela) and maintained in the animal care room at the Biochemistry Research Unit. The mice (5-10) were placed in $30 \times 30 \times 14 \mathrm{~cm}$ stainless steel cages, with free access to water and corresponding food, at an average temperature of $27^{\circ} \mathrm{C}$ and with light-dark $12 \mathrm{~h}$ periods.

All groups received a soft solid diet based on pre-cooked cornmeal, chicken eggs, coconut pulp milk; given an average composition of $67 \%$ carbohydrate, $28 \%$ protein and $5 \%$ fat. Since turmeric and pepper are highly hydrophobic substances, $5 \% \mathrm{w} / \mathrm{w}$ of ground turmeric (McCormick $®$ ) and $0.5 \% \mathrm{w} / \mathrm{w}$ black pepper (McCormick $囚$ ) were blend with the soft solid diet. Diet was daily fresh offered ad libitum, from seven 7 days prior to transplantation to trough all the experiments. Transplantation of the B16F10 melanoma cells was performed in the hind paw subcutaneous tissue, in a volume of $0.05 \mathrm{~mL}$ containing 200,000 malignant melanoma cells. Melanoma onset was diagnosed by an emergence of blackish macula on the place of xenotransplantation. Evolution of malignant melanoma disease was evaluated by the measure of body weight and quantification of tumor volume $\left(\mathrm{mm}^{3}\right)$ weekly using a vernier.

To decide euthanasia, animals were evaluated daily in search of clinical signs of seriously ill; these signs were anorexia, severe asthenia, and respiratory distress. Euthanasia was performed by exsanguinous, trough cardiac puncture, under deep anesthesia with pentobarbital and ketamine $(50 \mathrm{mg} / \mathrm{kg}$ of each one).

\subsection{Ethics}

The project was approved on January 24, 2014, by the Ethics Committee of the Health Sciences School, Universidad Centroccidental Lisandro Alvarado, Barquisimeto, Venezuela. Murine manipulation was performed according to the ethical criteria for the use of experimental animals of the National Endowment for Science Technology and Innovation (https://www.uis.edu.co/webUIS/es/investigacionExtension/comiteEtica/normatividad/documentos/otraNormativi dad/16 BioeticaVenezuela2002.pdf).

\section{$2.3 \quad$ Histology}

Tumor samples were fixed with 10\% PBS formaldehyde pH 7.2, dehydrated, included in paraffin, cut into $2 \mu \mathrm{m}$ sections, dewaxed and stained with hematoxylin-eosin.

\subsection{Elevated plus maze}

Anxiety was assessed at the second post-transplant week, using an elevated plus maze, consisting of 4 arms $50 \mathrm{~cm}$ long and $9.3 \mathrm{~cm}$ wide, built with medium density wood fiber (MDF), painted in opaque black color. $40 \mathrm{~cm}$ high walls surrounded two of the arms, while the open arm platforms directly led to the void. The maze was placed under a platform $81 \mathrm{~cm}$ high, oriented in such a way, that the closed arms were located from north to south. Initially the animal was placed in the open arm, living free to explore the maze for $10 \mathrm{~min}$. Time expended in each arm and entries from one arm to another were quantified.

\section{$2.5 \quad$ Hot plate}

The hot plate test was performed at the third week post-xenograft and was used to measure nociceptive responses. The experimental box had $31 \times 28 \mathrm{~cm}$ dimensions, walls and ceiling were made of transparent Plexiglas, and the floor was a thermo-conductive granite plate. Mouse were initially adapted to the experimental box for a period of 5 min at room temperature. The next day a mouse was put in the box at $50^{\circ} \mathrm{C}$ for a maximum period of $5 \mathrm{~min}$; nociceptive responses such as hind legs licks or jump were measured. As a control, test was also performed in healthy mice, inoculated or not with $1 \%$ carrageenan $(n=10)$, at subcutaneous level in the hind paw.

\subsection{Sample preparation for biochemical assays}

Spleen, liver, thymus and heart samples were cut into small pieces, suspended 1:10 w/v in $10 \mathrm{mM}$ tris buffer containing $0.1 \mathrm{mM}$ EDTA at pH 6.5. Homogenization was performed in 3 sessions using an Ultraturrax®, at 13,500 rpm for 1 min. Subsequently the sample was homogenized with a Teflon pistil, 3 sessions of 3 strokes each one; 5 min rest in ice was included between sessions. All samples were stored at $-70^{\circ} \mathrm{C}$ until use. Protein determination was done by Lowry's method. 


\subsection{Adenosine Deaminase (ADA) activity}

10-50 $\mu \mathrm{L}$ of the homogenized sample were resuspended in $1 \mathrm{~mL}$ of $50 \mathrm{mM}$ phosphate buffer (pH 6.5) containing $21 \mathrm{mM}$ adenosine, and incubated at $37^{\circ} \mathrm{C}$ for $60 \mathrm{~min}$; after which $3 \mathrm{~mL}$ of the phenol/sodium nitroprusside developer (106 mM phenol / $0.17 \mathrm{mM} \mathrm{NpNa}$ ) and $3 \mathrm{~mL}$ of alkaline hypochlorite solution (11 mM NaOCl / $125 \mathrm{mM} \mathrm{NaOH}$ ) were added and incubated for 30 minutes. The standard curve was performed with increasing concentrations (10-200 $\mu \mathrm{M})$ of ammonium sulfate. Finally, the color developed was measured at $620 \mathrm{~nm}$ in a spectrophotometer.

\subsection{Determination lipid peroxidation}

$100 \mu \mathrm{L}$ of liver homogenate was mixed with: $700 \mu \mathrm{L}$ of distilled water, $200 \mu \mathrm{L} 8.1 \%$ sodium dodecyl sulfate (SDS), 100 $\mu \mathrm{L} 0.22 \%$ butyl hydroxy-toluene (BHT) and $100 \mu \mathrm{L} \quad 0.27 \% \mathrm{FeCl}_{3}$; incubated $1 \mathrm{~h}$ at room temperature in the dark. Subsequently, $1.5 \mathrm{~mL} 20 \%$ acetic acid (pH 3.5) and $1.5 \mathrm{~mL} 0.8 \%$ thiobarbituric acid were added and incubated for $1 \mathrm{~h}$ at $95-100^{\circ} \mathrm{C}$. Standard curve was made from $0-100 \mu \mathrm{M}$ of 1,1,3,3-tetramethoxypropane (TMP) concentrations. The color developed was read at $540 \mathrm{~nm}$ in a spectrophotometer.

\subsection{Spice's dose-response curves}

Tumors were mechanically and progressively dissociated trough 18 to $25 \mathrm{G}$ need les, in $10 \%$ w/v physiological phosphate buffer (PPB) containing: $5 \mathrm{mM} \mathrm{Na}_{2} \mathrm{HPO}_{4}, 140 \mathrm{mM} \mathrm{NaCl}, 5 \mathrm{mM} \mathrm{KCl}, 1 \mathrm{mM} \mathrm{CaCl}, 1 \mathrm{mM} \mathrm{MgCl}$, $5 \mathrm{mM} \mathrm{glucose}_{2} 6$ $\mu \mathrm{M}$ fluconazole, $1 \mathrm{mg} / \mathrm{mL}$ ampicillin, $10 \mu \mathrm{g} / \mathrm{mL}$ enrofloxacin and $50 \mu \mathrm{M}$ phenol red, $\mathrm{pH}$ 8. Cell viability was determined using Trypan blue. For dose response curve, $200 \mu \mathrm{L}$ of dissociated cells were re-suspended in $2 \mathrm{~mL}$ PPB with increasing concentrations ( $1 \mu \mathrm{g}$ to $1 \mathrm{mg} / \mathrm{mL}$ ) of pepper and turmeric, incubated in 24 -well plates for 24 hours at $37^{\circ} \mathrm{C}$, then pH of each well was measured using a Corning® 340 digital pH meter.

\subsection{MTT assay}

$20 \mu \mathrm{L}$ of MTT was added to $100 \mu \mathrm{L}$ of cultured cells, incubated for 4 hours at $37^{\circ} \mathrm{C}$, centrifuged at $5000 \mathrm{rpm}$ for $10 \mathrm{~min}$; the pellet was dissolved with DMSO using vortex. Absorbance read at $590 \mathrm{~nm}$ with a reference filter of $620 \mathrm{~nm}$

\subsection{Statistical analysis}

All data are presented as the average \pm the standard error (SE). To establish if there were significant differences between groups, an ANOVA or Kruskal Wallis tests were performed followed by the Tukey's or Dunn's post tests, respectively, according to sample distribution. Macula onset time and survival were estimated by the Kaplan-Meier method and the log-rank (Mantel-Cox) test was performed to test the difference in survival between groups. DI50 was calculated by nonlinear regression using four parameters dose response fitting. A p value $<0.05$ was considered statistically significant. All analyzes were performed using the GraphPad Prism 4® program.

\section{Results}

A total of 96 mice (93.20\% of the initial sample) developed malignant melanoma and 7 mice (6.79\%) did not develop any kind of tumor. Macula onset was observed between 12 and 21 post-xenograft days, with average times of 22, 17, 14 and 12 days for Turpepp, Pepper, Turmeric and Control groups, respectively. Analysis of the time curves by the Logrank test (Mantel-Cox) showed a significant difference between Turpepp and Pepper, with respect to the control group (see Figure 1, Panel A). To corroborate these results, we did an analysis using macula onset absolute values; obtaining that mice treated with Turpepp and Pepper showed a significantly $(\mathrm{p}<0.0001)$ longer time, in relation to the mice of the Control group, with an average onset time of $21.69 \pm 1.33,18.32 \pm 1.01$ and $13.84 \pm 0.65$ days for Turpepp, Pepper and Control groups, respectively; while Turmeric group showed a time of $14.56 \pm 0.61$ days (see Figure 1, Panel B). In addition, Turpepp and Pepper groups had a significantly longer survival time when compared to the control group. The median survival times were 39, 34, 37 and 28 for Turppep, Pepper, Turmeric and Control groups, respectively. 
A

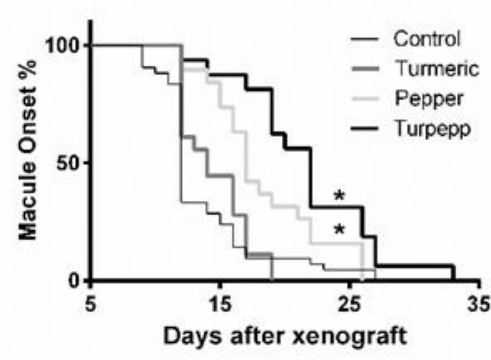

B

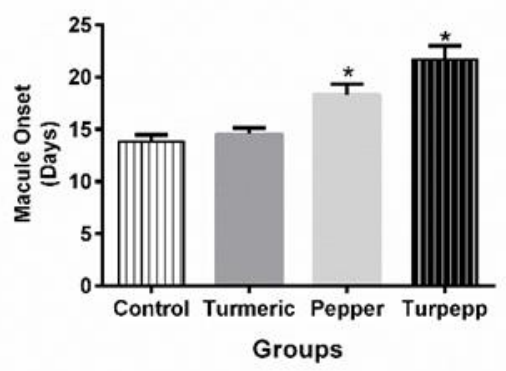

C

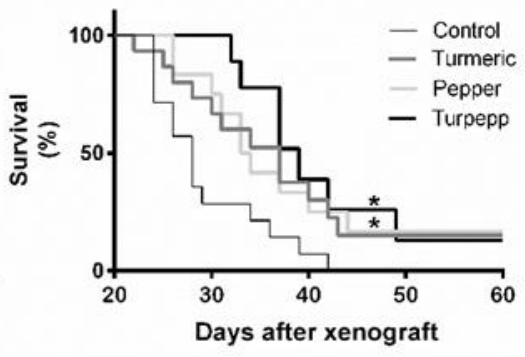

Figure 1 Melanoma macule onset and survival in mice treated with Turmeric and/or Pepper. Mice were transplanted with 200.000 malignant melanoma cells in the right hind paw. In panel A days to macule onset after xenograft, in B mean \pm SEM of days to macula onset and in C survival curve are displayed, respectively. Lines of panels A and C fitted by the Kaplan-Meier method and analyzed by log-rank test. * means $\mathrm{p}<0.05$ as compared with Control group using Kruskal Wallis test followed by Dunn's multiple comparisons post hoc.

Tumor volume clinical evolution was progressive in crescendo from macula onset. At 12 days post-xenograft: Turpepp, Pepper and Turmeric groups had a significantly lower tumor volumes when analyzed with respect to the Control group, while for days 19 and 26 post-transplant, tumor volumes were significantly lower for Turpepp and Pepper groups, when compared to the Control group. When analyzing tumor weight, at the time of the autopsy, it was evident that the tumor weight was lower in Turpepp group, reaching statistical significance $(p=0.018)$, as compared to Control group. In the same way, tumor growth rate was lower in Pepper and Turpepp groups, without reaching statistical significance (see Figure 2).
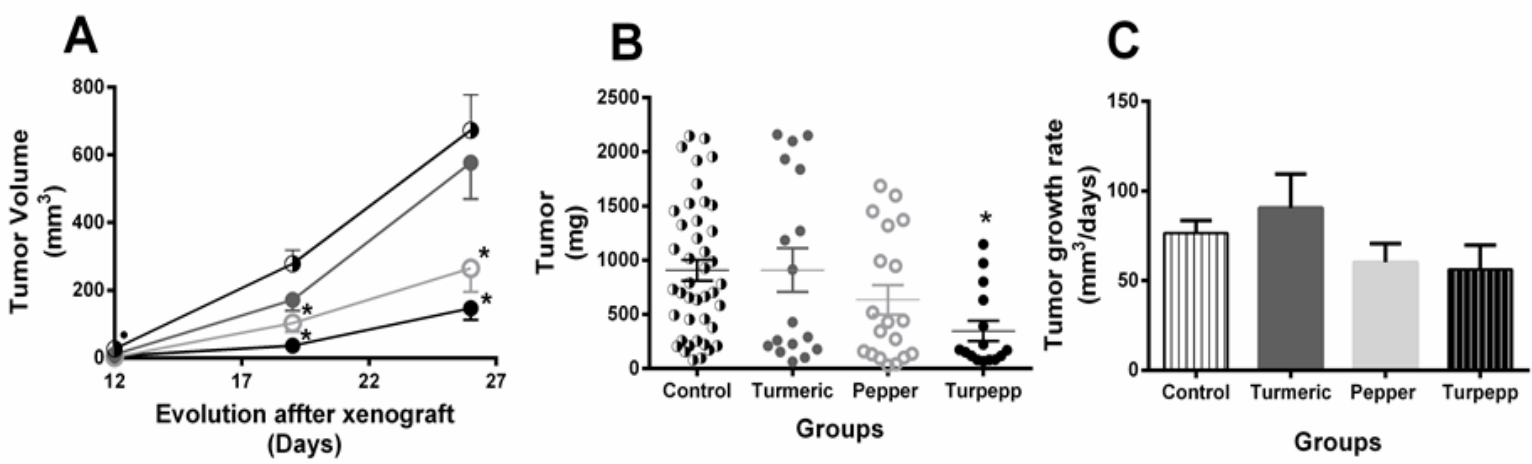

Figure 2 Evolution of the tumor volume in C57Bl/6 mice with malignant melanoma. Half-filled black circle, filled gray circles, empty gray circle and black filled circles represent Control, Turmeric, Pepper and Turpepp groups, respectively. Observe that tumors of either Pepper, as well as Turpepp group, grow significantly more slowly at 12, 19 and 26 days. Tumors of Turmeric mice were smaller at 12 , but at 19 and 26 days their volumes were similar to the control groups. * means $\mathrm{p}<0.05$ as compared with Control group using Anova test followed by Tukey's post hoc.

Table 1 shows the characteristics of the tumor during autopsy. The net tumor weight and normalized weight were significantly lower for Turppep group as compared to Control group, and tumor volume was lower in Turppep group, without reaching statistical significance. 
Table 1 Primary tumor characteristics in C57Bl/6 mice with malignant melanoma treated with turmeric and/or pepper.

\begin{tabular}{|l|l|l|l|l|l|}
\hline \multirow{2}{*}{} & \multirow{2}{*}{ Parameter } & \multicolumn{4}{|c|}{ Groups } \\
\cline { 2 - 6 } & Control & Turmeric & Pepper & Turpepp \\
\hline \multirow{3}{*}{$\begin{array}{l}\text { Primary } \\
\text { Tumor }\end{array}$} & Net weight $(\mathrm{mg})$ & $885.60 \pm 95.72$ & $858.50 \pm 197.1$ & $574.30 \pm 129.10$ & $305.90 \pm 86.64^{*}$ \\
\cline { 2 - 6 } & Indexed weight $(\mathrm{mg} / \mathrm{g})$ & $58.44 \pm 6.03$ & $59.46 \pm 12.95$ & $47.56 \pm 10.47$ & $25.85 \pm 7.32^{*}$ \\
\cline { 2 - 6 } & \begin{tabular}{l} 
Tumor volume $\left(\mathrm{mm}^{3}\right)^{*}$ \\
\cline { 2 - 6 }
\end{tabular} & $1247 \pm 156.10$ & $1450 \pm 399.50$ & $739.60 \pm 187.00$ & $595.30 \pm 151.60$ \\
& $\begin{array}{l}\text { Indexed tumor volume } \\
\left(\mathrm{mm}^{3} / \mathrm{g}\right)\end{array}$ & $81.14 \pm 11.01$ & $77.83 \pm 20.57$ & $58.08 \pm 15.30$ & $46.05 \pm 12.25$ \\
\cline { 2 - 7 } & $\begin{array}{l}\text { Tumor growth rate } \\
\left(\mathrm{mm}^{3} / \mathrm{day}\right)\end{array}$ & $76.55 \pm 7.05$ & $90.57 \pm 18.88$ & $60.28 \pm 10.44$ & $56.30 \pm 13.46$ \\
\hline
\end{tabular}

Figure 3 shows Control (upper panel) and Turpepp (lower panel) tumors at the time of autopsy. It can be seen that Control group tumors were larger, lobed, with broad ulcerations, thin epidermis and intense red wine color. On the contrary, Turpepp group tumors were smaller, pale, showing small ulcerations with scar response and unscathed epidermis.

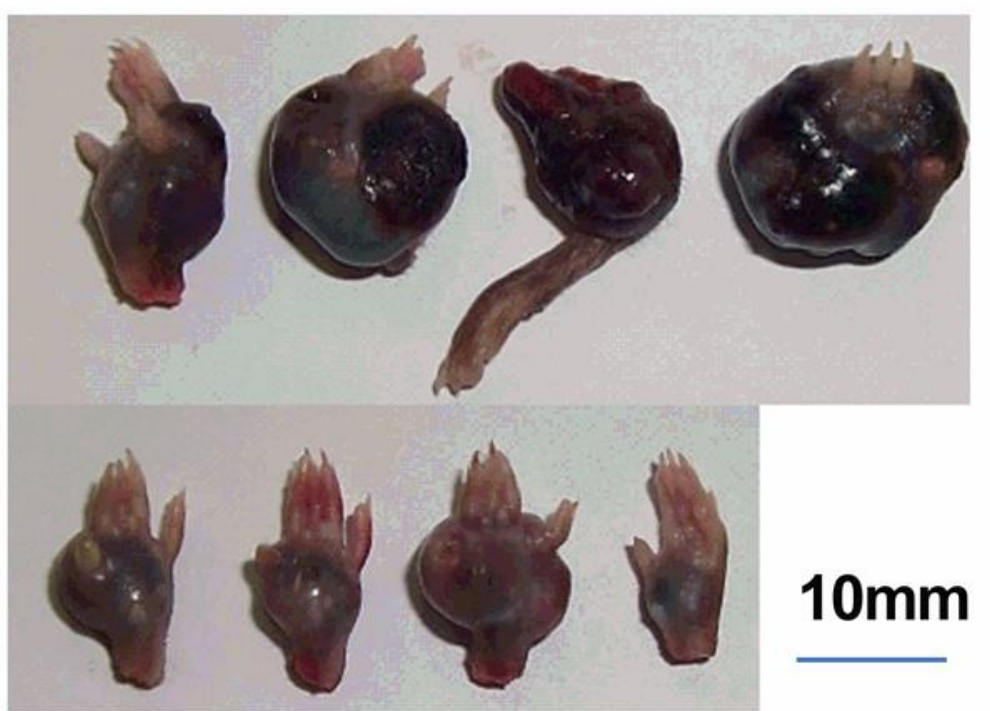

Figure 3 Tumors obtained from autopsies. Photographs shows tumoral hind legs obtained from 4 different animals for each group: Control (upper) and Turpepp (bottom). Besides the evident increase in volume, control tumors are irregular, turgid and dark purple color; skin looks thin with wide ulcerated areas. On the contrary, Turppep tumors are smaller, with regular surfaces; skin with overall integrity preserved and most of the tumors had no ulcers. Horizontal bar is equal to $10 \mathrm{~mm}$.

Figure 4 shows illustrative histopathological sections of the Control group (panels A and B), Turpepp (C and D) and Pepper (E and F) tumor samples. Typical characteristics of malignant melanoma tumor tissue can be evidenced in pictures from Control group, being tumor loose with small-interspersed foci of eosinophilic necrosis and small blood vessels; melanoma cells were epithelial in appearance, with well-defined borders losing intercellular contact, amphophilic cytoplasm and nucleus with several nucleoli. In sections of pepper's sample, tumor have an eosinophilic compact area with few pale nuclear granulations without vessels, at higher magnification no structural cell are visible, only degenerated nuclei (ghost cells) surrounded by homogeneous and compact interstitial tissue; these characteristics define a coagulative necrosis, which tend to occupy more than $50 \%$ of the tumor sample. In sections of Turpepp sample, tumor had mixed characteristic with eosinophilic areas of coagulative necrosis and abundant large blood vessels, a higher magnification ghost cells are visible in a more organized interstitial tissue, with few pale nuclear granulations without vessels. 

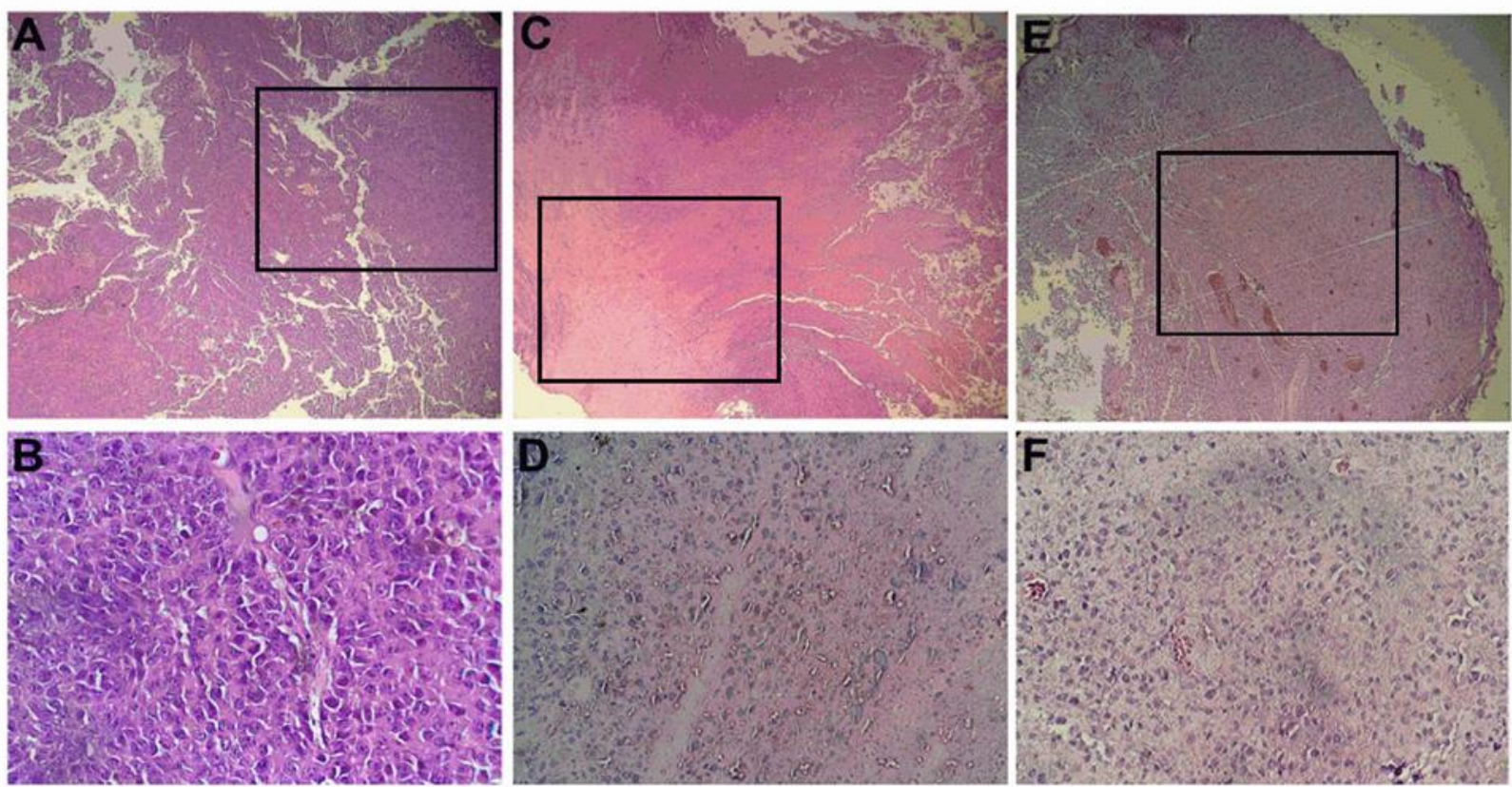

Figure 4 Histopathological features of melanoma tumors. Samples were stained with hematoxilin-eosin. Left (A and B), medial (C and D) and right figures (E and F) are from Control, Pepper and Turpep group tumor samples, respectively. Upper are at 75X augment and lower figures at 400X. Observe that Pepper's sample show large area of coagulative necrosis characterized by a homogenous eosinophilic radial zone indicated by arrow, where no cellular structures are visible (panel C, arrow), at higher magnification it can be observed that there are no defined cell structures, only degenerated nuclei (ghost cells) in a dense and homogeneous extracellular matrix (panel D). Turpepp sample display similar characteristics as Pepper's samples.

Pepper and Turpepp mice showed greater weight loss, when compared to the Control and Turmeric groups, being the values statistically significant when comparing Turpepp against Control. Given that treated mice showed a surprising greater weight loss, while presenting a lower develop of primary tumor, prompted us to carry out a more detailed analysis. Tumors were classified: as more developed having weights greater than $500 \mathrm{mg}$, and less developed displaying weights lower than $500 \mathrm{mg}$, then we proceed to do a correlation analyses between weight loss and tumor weight, in both control and experimental groups. We obtained that control mice with tumor over $500 \mathrm{mg}$, lost more weight as the tumor got bigger, while mice with less develop tumor no significant correlation was observed (Figure 5, Panel B). In the experimental groups we observed the opposite, the smaller the tumor the greater the weight loss, a fact that was true for both, mice with tumors greater or less than $500 \mathrm{mg}$, and also for all experimental mice analyzed together (see Figure 5, Panel C).

A

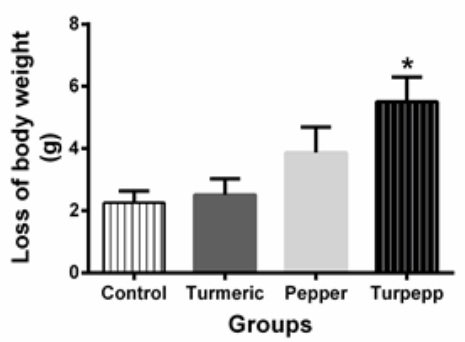

Groups

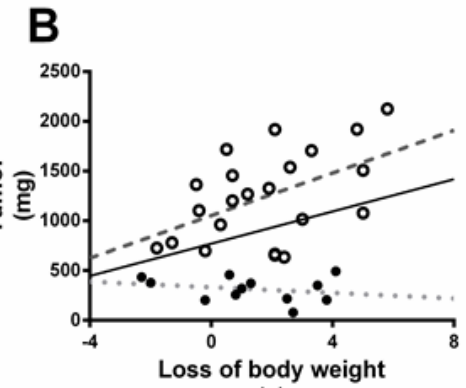

(g)

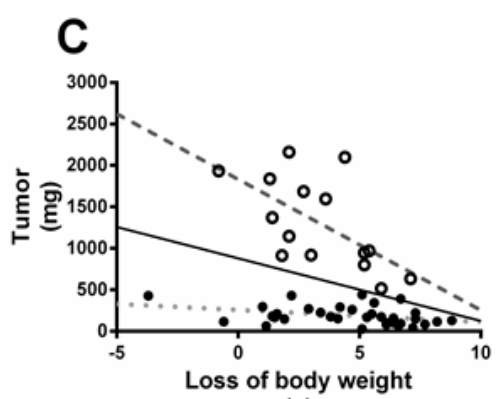

(g)

Figure 5 Loss of body weight in mice as consequence of malignant melanoma. Body weight loss defined as the different between autopsy body weight and the weight when spices diet administration starts. In A we can observe that all the experimental groups lost weight, especially Pepper and Turpepp groups, being statistically significant for the latest group. Panels $\mathrm{B}$ and $\mathrm{C}$ shows a correlation analyses between tumor net weight at autopsy and corporal weight loss in Control (B) and experimental (C) groups. Empty circles and gray dashed líneas, represent the analyses for individuals 
with tumor over $500 \mathrm{mg}$ and filled circles and gray dotted lines tumors below $500 \mathrm{mg}$ weight, continuous black lines represent the analyses for all individuals. Observe that in control mice there was significant positive correlation between tumor weight and weight lost in individuals with tumors over 500 mgs $(r=-0.496 ; r 2=0.246, p=0.018)$, while in tumors below 500 mgs correlation was negative but not significant, similar to the global analyses. On the contrary, in experimental groups negative significant correlations (lower tumor weight greater weight loss) were observed for all groups and tumor weights (continuous line; $r=-0.337 ; \mathrm{r} 2=0.114 ; \mathrm{p}=0.014)$, for tumor weight below than $500 \mathrm{mg}(\mathrm{r}=$ $-0.392, \mathrm{r} 2=0.246, \mathrm{p}=0.018)$ and for tumor weight above $500 \mathrm{mg}(\mathrm{r}=-0.618 ; \mathrm{r} 2=0.382 ; \mathrm{p}=0.014){ }^{*}$ means $\mathrm{p}<0.05$ as compared with Control group using Anova test followed by Tukey's post hoc.

Given the clear relationship between tumor weight and body weight loss, we decided to expand the analysis for all variables, comparing mice with indexed tumor weight less than $57 \mathrm{mg} / \mathrm{g}$ with mice with heavier tumors (> $57 \mathrm{mg} / \mathrm{g}$ ). The results showed that mice weighing less than $57 \mathrm{mg} / \mathrm{g}$ had a significantly greater loss of body weight, results that were particularly reproduced in the Turmeric, Pepper and Turppep groups; which additionally showed a significant increase in thymus net and normalized weight, particularly in the Pepper group; while on the contrary Control group presented significantly lower thymus weights. Mice with weights greater than $57 \mathrm{mg} / \mathrm{g}$ had significantly higher spleen weights, results that were particularly reproduced by the Control and Turmeric group. In addition, pepper group presented a significant increase in both net liver and heart weights (see 5 Figure and Table 4).

Table 4 Comparison in corporal and organs weight, according to indexed primary tumor weight in C57Bl/6 mice with malignant melanoma during autopsy.

\begin{tabular}{|c|c|c|c|c|c|c|c|c|c|}
\hline \multirow{2}{*}{\multicolumn{2}{|c|}{ Parameter }} & \multicolumn{8}{|l|}{ Groups } \\
\hline & & \multicolumn{2}{|l|}{ Control } & \multicolumn{2}{|l|}{ Turmeric } & \multicolumn{2}{|l|}{ Pepper } & \multicolumn{2}{|l|}{ Turpepp } \\
\hline & & $<57$ & $>57$ & $<57$ & $>57$ & $<57$ & $>57$ & $<57$ & $>57$ \\
\hline Body & BWL & $-2.6 \pm 0.6$ & $-1.9 \pm 0.5$ & $-4 \pm 0.4^{\circ}$ & $-2.1 \pm 0.5$ & $-5.1 \pm 0.8^{\circ *}$ & $-2 \pm 0.4$ & $-6 \pm 0.8^{\circ *}$ & $-3.9 \pm 0.8$ \\
\hline \multirow{2}{*}{ Liver } & W & $793.8 \pm 40.4$ & $855 \pm 35.8$ & $812.8 \pm 83.2$ & $827.7 \pm 57.4$ & $943.6 \pm 6.5^{\circ}$ & $759.8 \pm 8.9$ & $799.4 \pm 3.9$ & $664.8 \pm 7.8$ \\
\hline & IW & $53.1 \pm 1.9$ & $53.7 \pm 1.5$ & $62.8 \pm 4.2$ & $54 \pm 1.7$ & $58.8 \pm 2.5$ & $58.1 \pm 1.9$ & $56.6 \pm 4.6$ & $51.5 \pm 1.2$ \\
\hline \multirow{2}{*}{ Spleen } & W & $105 \pm 13.1$ & $180 \pm 13.9^{\circ *}$ & $58.5 \pm 13.7^{*}$ & $112 \pm 20^{\circ}$ & $119.3 \pm 23$ & $108.3 \pm 31.2$ & $34.6 \pm 12.2^{*}$ & $20.3 \pm 4.5$ \\
\hline & IW & $7 \pm 0.8$ & $11.4 \pm 0.9^{\circ *}$ & $3.6 \pm 0.4^{*}$ & $7.4 \pm 1.3^{\circ}$ & $8.3 \pm 2$ & $8.3 \pm 2.3$ & $5.5 \pm 1.4^{*}$ & $5.4 \pm 1.4$ \\
\hline \multirow{2}{*}{ Thymus } & W & $31.2 \pm 3.4$ & $22.9 \pm 1.7^{\circ}$ & $16 \pm 3$ & $26.1 \pm 3.7$ & $64.4 \pm 18.8^{\circ *}$ & $20.8 \pm 3.2$ & $34.6 \pm 12.2$ & $20.3 \pm 4.5$ \\
\hline & IW & $2 \pm 0.2$ & $1.4 \pm 0.1$ & $1.9 \pm 0.8$ & $1.8 \pm 0.3$ & $2.3 \pm 0.5$ & $1.6 \pm 0.5$ & $2.2 \pm 0.6$ & $1.6 \pm 0.4$ \\
\hline \multirow{2}{*}{ Heart } & W & $103.8 \pm 5.2$ & $109 \pm 6.9$ & $89.5 \pm 3.9$ & $98.5 \pm 6.2$ & $104 \pm 6.8^{\circ}$ & $85.5 \pm 6.2$ & $95 \pm 9.1$ & $98 \pm 9.8$ \\
\hline & IW & $6.8 \pm 0.4$ & $6.8 \pm 0.3$ & $6.4 \pm 0.6$ & $6.5 \pm 0.4$ & $6.4 \pm 0.8$ & $6.3 \pm 0.6$ & $6.4 \pm 1$ & $7.6 \pm 0.3$ \\
\hline
\end{tabular}

Indexed tumor weight were divided in $<57$ and $>57 \mathrm{mg} / \mathrm{g}$ of corporal weight, respectively, W: weight in g, BWL: Body Weight Lost in grs; IW: Indexed Weights in $\mathrm{mg} / \mathrm{gr}$ of corporal weight, Organ weights in mg. ${ }^{\circ}$ means $\mathrm{p}<0.05$ as intergroup. ${ }^{*}$ means p $<0.05$ as comparation with Control group.

Total metastases were significantly lower in the Turpepp group compared to the Control group; also Turpepp group together with the Pepper group showed less lymph node metastases without reaching statistical significance. Likewise, a smaller number of mice in Pepper $(n=3 ; 14.29 \%)$ and Turpepp $(n=2 ; 11.11 \%)$ groups presented pulmonary metastases, as compared with Control $(n=12 ; 27.27 \%)$ and Turmeric $(n=6 ; 30 \%)$. When pulmonary metastasis were analyzed using contingency tables, we obtained a statistically significant difference between Pepper or Turpepp groups with respect to the control group (see Figure 6). 
A

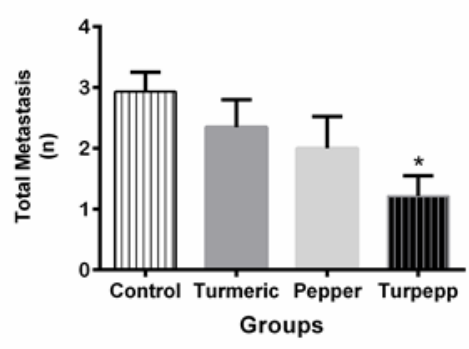

B

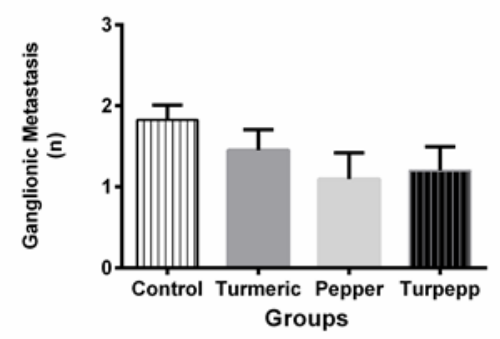

C

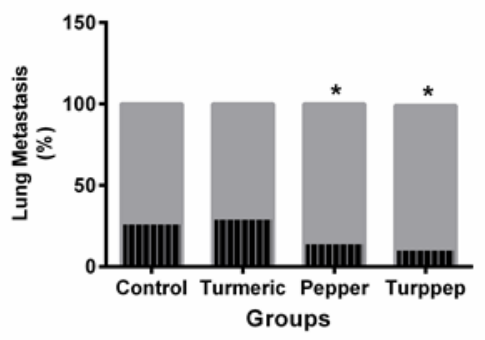

Figure 6 Metastasis in mice with malignant melanoma. In Turpepp group the mean number of total metastasis was significant lower as compared with Control group (Panel A), however, the mean number of ganglionic metastasis were not significant (Panel B). Similarly, Pepper and Turpepp groups were significantly associated with a lesser number of lung metastasis. * means $\mathrm{p}<0.05$ as compared with Control group using Anova test followed by Tukey's post hoc for A and $\mathrm{B}$, and $\mathrm{C}$ by Chi2 test.

Nociceptive functional integrity evaluated in both tumor and healthy legs by means of the hot plate test, showed that the nociceptive response (lick of the leg) was significantly decreased in the tumor legs for all experimental groups, when compared with the homo-lateral non-tumor paw of healthy mice (Figure 7, Panel A). However, when analyzing the nociceptive response in the non-tumor legs, we observed that both healthy and Turpepp groups displayed nociceptive responses, with significantly shorter latency times, while the Control, Turmeric and Pepper groups presented latency times greater than 200 seconds (Figure 7, Panel B).
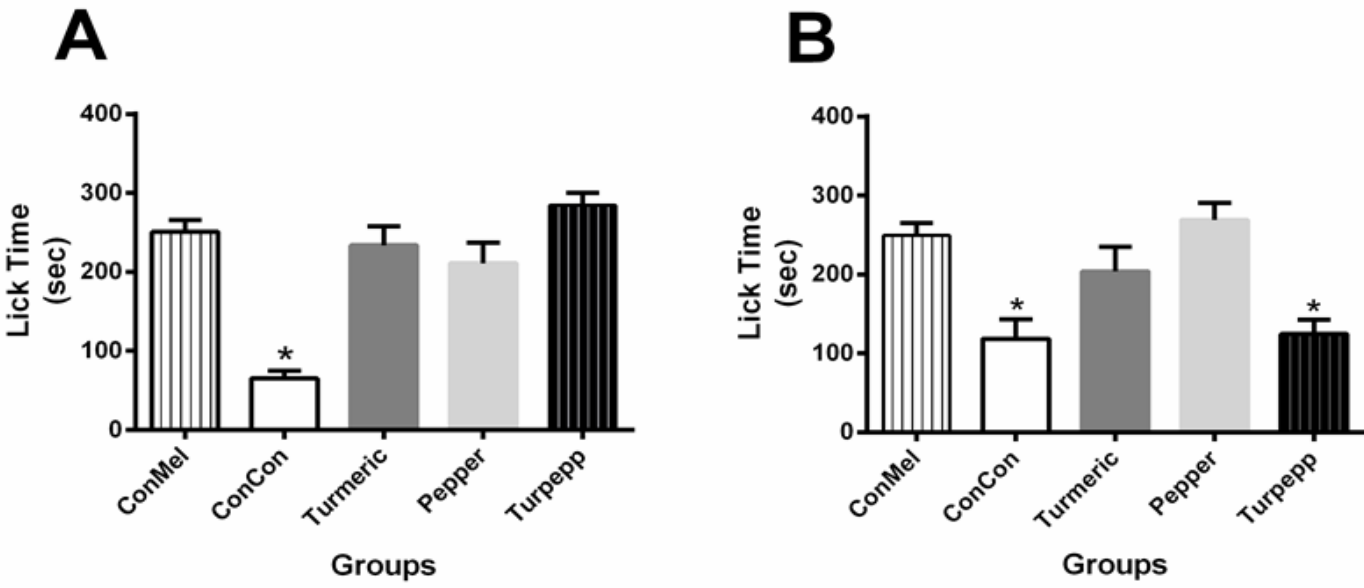

Figure 7 Nociceptive behavior tested by means of hot plate test in mice with malignant melanoma. In this test, latency time for licking the hind legs in the hot plate were measured for each mouse individually. Nociceptive behavior (time to licking) was significantly increased in the hind leg bearing the melanoma tumors in all groups as compared with a healthy mice group (ConCon group, Panel A), however, for non tumoral hind legs Turppep group show similar nociceptive behavior as healthy mice group did (Panel B). * means $\mathrm{p}<0.05$ as compared with Control group using Anova test followed by Tukey's post hoc.

The analysis of the behavior observed in the elevated plus maze showed that the Turpepp group presented greater motility expressed in a significantly greater number of total entrances to open and closed arms, entering preferably to closed arms from a closed arm $(\mathrm{p}<0.05)$ (see Table 3$)$. 
Table 3 Performance of C57Bl/6 mice with malignant melanoma and treated with turmeric or pepper on elevated plus maze.

\begin{tabular}{|c|c|c|c|c|}
\hline \multirow{2}{*}{ Parameter } & \multicolumn{4}{|l|}{ Groups } \\
\hline & Control & Turmeric & Pepper & Turpepp \\
\hline Total arm entries & $48.36 \pm 3.31$ & $41.29 \pm 4.14$ & $55.21 \pm 3.99$ & $71.00 \pm 4.14^{*}$ \\
\hline Open arm entries & $5.36 \pm 0.63$ & $6.00 \pm 0.93$ & $6.14 \pm 0.98$ & $6.60 \pm 0.79$ \\
\hline Closed arm entries & $19.71 \pm 1.29$ & $15.00 \pm 1.25$ & $21.86 \pm 1.34$ & $29.40 \pm 1.60^{*}$ \\
\hline Time in open arms & $48.93 \pm 9.27$ & $50.14 \pm 9.49$ & $45.14 \pm 10.12$ & $53.30 \pm 9.63$ \\
\hline Time in closed arms & $440.60 \pm 18.43$ & $481.60 \pm 15.31$ & $429.70 \pm 18.10$ & $437.0 \pm 17.60$ \\
\hline $\begin{array}{l}\text { Closed } \rightarrow \text { Closed arms } \\
\text { displacements }\end{array}$ & $12.71 \pm 1.26$ & $8.00 \pm 0.67^{*}$ & $14.79 \pm 1.22$ & $20.40 \pm 1.85^{*}$ \\
\hline $\begin{array}{l}\text { Closed } \leftrightarrow \text { open arms } \\
\text { displacements }\end{array}$ & $8.36 \pm 1.29$ & $9.07 \pm 1.53$ & $8.57 \pm 1.28$ & $9.60 \pm 1.18$ \\
\hline $\begin{array}{l}\text { Open } \rightarrow \text { Open arms } \\
\text { displacements }\end{array}$ & $0.71 \pm 0.19$ & $0.79 \pm 0.24$ & $1.21 \pm 0.45$ & $0.80 \pm 0.39$ \\
\hline
\end{tabular}

To corroborate whether turmeric or pepper had a direct effect on melanoma cells, we measured anaerobic metabolism and cell viability in dissociated cells from primary tumors cultured in vitro (see Materials and Methods). The results showed that pepper exhibited greater potency in both types of assay, with DI50 values of $124.30 \pm 2.48$ and $15.93 \pm 0.20$ $\mu \mathrm{g} / \mathrm{mL}$, for anaerobic metabolism and cell viability, respectively; while for turmeric we obtained DI 50 values of 328.70 \pm 4.46 and $91.31 \pm 4.80 \mu \mathrm{g} / \mathrm{mL}$, respectively (see Figure 8). Note that the inhibitory potency is best visualized in MTT cell viability assay.
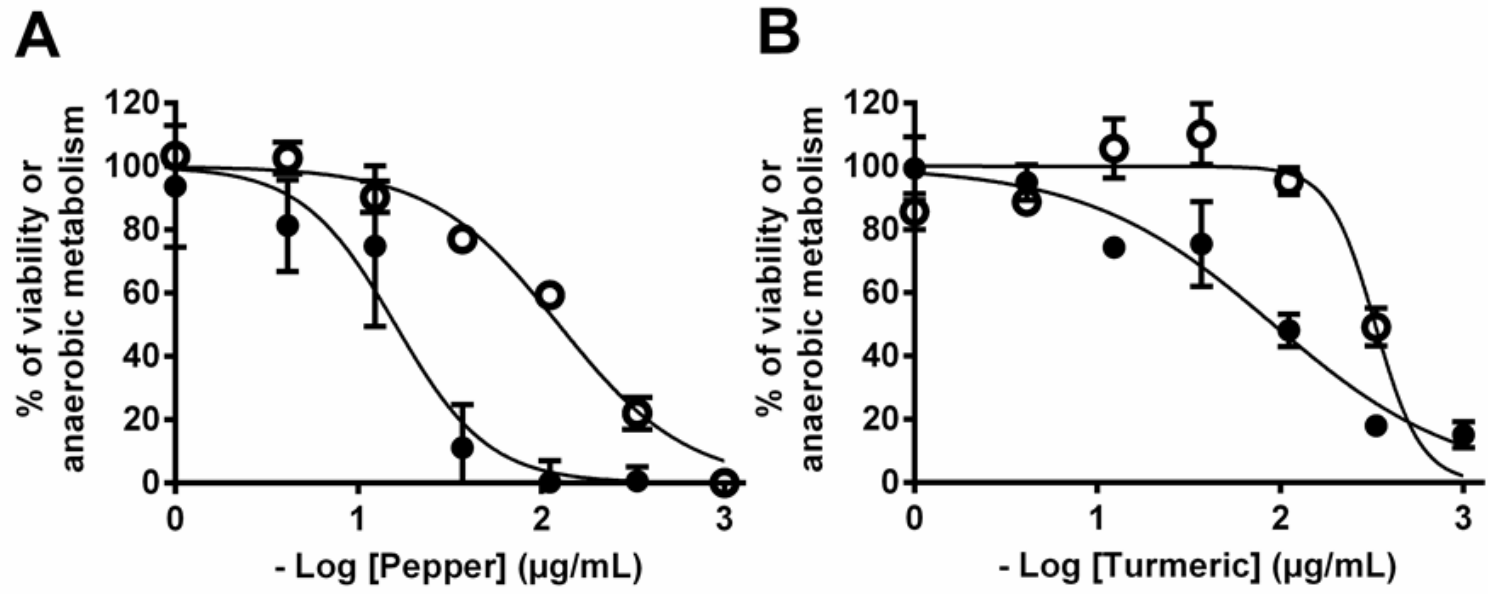

Figure 8 Effect of pepper and turmeric on anaerobic metabolism and viability of melanoma cells. Anaerobic metabolism determined by pH change after 24 hours of cell culture (unfilled circles) and viability determined by MTT assay (filled circles). In panel A and B pepper and turmeric dose response curves, respectively. Observe that, both compounds showed high potency in viability assays, having pepper more potency for both assays as compared with turmeric. IC50 were $124.30 \pm 2.48$ and $328.70 \pm 4.46 \mu \mathrm{g} / \mathrm{ml}$ (anaerobic metabolism) and $15.93 \pm 0.20$ and $91.31 \pm 4.80 \mu \mathrm{g} / \mathrm{ml}(\mathrm{MTT}$ viability) for turmeric and pepper, respectively.

When analyzing tecidual proteins, statistically significant differences for Turmeric and Pepper groups in thymus were observed, as compared with control group. ADA enzyme activity decreased in thymus in the Turpepp group and was significantly higher in Turmeric and Pepper groups, compared to Control group (see Table 2). 
Table 2 Visceral organ weights and biochemistry parameters from mice with malignant melanoma treated with turmeric and/or pepper.

\begin{tabular}{|c|c|c|c|c|c|}
\hline \multirow{2}{*}{ Organ } & \multirow{2}{*}{ Parameters } & \multicolumn{4}{|l|}{ Groups } \\
\hline & & Control & Turmeric & Pepper & Turpepp \\
\hline \multirow{5}{*}{ Liver } & Net weight & $821.60 \pm 27.48$ & $866.20 \pm 48.67$ & $865.90 \pm 40.82$ & $735.40 \pm 35.91$ \\
\hline & Indexed weight & $53.34 \pm 1.24$ & $58.16 \pm 2.35$ & $58.57 \pm 1.80$ & $53.25 \pm 1.92$ \\
\hline & Proteins & $209.20 \pm 28.89$ & $276.40 \pm 58.69$ & $268.70 \pm 64.04$ & $309.30 \pm 56.35$ \\
\hline & ADA & $472.80 \pm 50.69$ & $391.90 \pm 10.41$ & $424.90 \pm 58.14$ & $429.20 \pm 65.83$ \\
\hline & Lipid peroxidation & $32.08 \pm 5.45$ & $23.92 \pm 1.58$ & $24.47 \pm 2.46$ & $27.42 \pm 3.18$ \\
\hline \multirow{4}{*}{ Spleen } & Net weight & $139.10 \pm 11.02$ & $86.67 \pm 13.60^{*}$ & $115.60 \pm 18.05$ & $79.09 \pm 14.27^{*}$ \\
\hline & Indexed weight & $8.99 \pm 0.67$ & $6.05 \pm 0.89$ & $8.27 \pm 1.48$ & $5.90 \pm 1.24$ \\
\hline & Proteins & $221.70 \pm 30.35$ & $178.20 \pm 22.20$ & $227.00 \pm 25.66$ & $182.10 \pm 5.76$ \\
\hline & ADA & $1313 \pm 237.00$ & $1556 \pm 273.50$ & $1165 \pm 230.10$ & $1654 \pm 216.70$ \\
\hline \multirow{4}{*}{ Thymus } & Net weight & $27.78 \pm 2.15$ & $26.07 \pm 3.70$ & $40.27 \pm 10.71$ & $28.22 \pm 7.12$ \\
\hline & Indexed weight & $1.77 \pm 0.13$ & $1.81 \pm 0.29$ & $2.68 \pm 0.79$ & $1.92 \pm 0.35$ \\
\hline & Proteins & $168.30 \pm 24.04$ & $77.18 \pm 24.53^{*}$ & $73.16 \pm 14.79 *$ & $129.50 \pm 19.14$ \\
\hline & ADA & $2127 \pm 295.20$ & $3546 \pm 653.60^{*}$ & $3707 \pm 751.00 *$ & $1930 \pm 271.10$ \\
\hline \multirow{4}{*}{ Heart } & Net weight & $106.60 \pm 9.43$ & $95.93 \pm 4.58$ & $93.25 \pm 5.44$ & $96.33 \pm 6.29$ \\
\hline & Indexed weight & $6.81 \pm 0.26$ & $6.45 \pm 0.29$ & $6.37 \pm 0.45$ & $6.92 \pm 0.59$ \\
\hline & Proteins & $90.68 \pm 28.89$ & $103.70 \pm 12.35$ & $96.39 \pm 10.26$ & $93.65 \pm 16.78$ \\
\hline & $\mathrm{ADA}$ & $82.48 \pm 7.17$ & $72.19 \pm 10.41$ & $99.68 \pm 13.86$ & $87.88 \pm 13.64$ \\
\hline
\end{tabular}

ADA: Adenosine Deaminase Activity; Parameter units are: net weight in mg, indexed weight mg/g of corporal weight, Proteins mg/g of tissue, ADA $\mathrm{nmol}$ of adenosine/mg of protein, lipid peroxidation nmol malondialdehyde/mg of tissue. *means $\mathrm{p}<0,05$ with respect to Control group.

\section{Discussion}

In the present paper, we demonstrate that the combined preventive treatment of Curcuma longa and Piper nigrum, increased the latency time for macula onset, decreased tumor volume and weight, decreased metastases number and decreased mortality, facts that were translated into a better signs of physical well-being as greater motility, preserved nociceptive response and increased survival. Results of combined treatment were reproduced in pepper group, but with less statistical force, however, pepper showed greater potency in vitro, for both metabolic and cell viability experiments. The most novel aspect of this work is to demonstrate anti-proliferative effect that pepper has on malignant melanoma, both in vivo and in vitro.

Our protocol included a previous administration of medicinal plants based diet before xenograft, that was done with the aim to confirm the security of turmeric and pepper treatment on animals' welfare, and to determine their preventive effects on cancer development. Carcinogenesis is a crucial concept to understand prevention based-protocols. Cancer is a genetic, inflammatory and immunologic disease regarded to a pathogenic point of view. To develop cancer, accumulations of inherited and acquired mutations are needed; these mutations must affect oncogenes and tumor suppressor genes. Simultaneously, tumor inflammation generate a great production of free radicals that induce these genotoxic changes in DNA. Lately, clonal selection of proliferative, trophic, angiogenic and autonomous cancer cells induced by accumulative mutations leads to tumor generation. Finally, a failure in apoptosis, in the immunosurveillance follow by immune tolerance, allow tumor to growth in local cancer environment, disseminate and colonize distant tissue. In these carcinogenic events, medicinal plant could have vital effects as anti-inflammatory, immunogenic, proapoptotic and cytotoxic effect on transformed cancer cells.

The main chemopreventive mechanisms of action of pepper-contain piperine include protection against oxidative stress by quenching ROS, free radicals and reactive metabolic intermediates, being a potent antioxidant [12, 13]. Also, Piperine enhance cellular and immune response [14], causing an increase of Th1 helper T lymphocytes cytokine profile levels (IL-1 $\beta$, TNF- $\alpha$, IL-12) and a decrease of Th2 cytokine profile (IL-4, IL-10) [15], these immunological reprograming favor immunosurveillance and avoid immunotolerance, supporting cytotoxic antitumoral response. Additionally, piperine 
activate apoptotic-signaling cascades, inhibit cell proliferation by cell cycle arrest, modulate ER stress and autophagy and inhibit angiogenesis [16].

Curcumin also has antioxidant, anti-inflammatory, immunogenic, proapoptotic and inhibition of survival signals properties [17]. Curcumin is capable of scavenging a reactive oxygen species and other organic free radicals [18] and inhibit cyclooxygenase-2 (COX-2), lipoxygenase (LOX), and inducible nitric oxide synthase (iNOS) [19], delineating its anti-inflammatory and antioxidant effects. On the immune system curcumin promote proliferation of CD4+/CD8+ T cell populations, avoid type- 2 cytokine bias, reduce Treg cell population and suppress $\mathrm{T}$ cell apoptosis; all these help to maintain tumor immune surveillance that leads to cancer cells killing [20].

Therefore, turmeric and pepper that contains curcumin and piperine, respectively, as a main active compounds, fulfills the characteristics for an ideal chemopreventive medicinal plants with low toxicity, affordability, and easy accessibility.

Turmeric and pepper anticancer effect has been extensively studied both in vitro and in vivo models. Curcuma longa and its active compounds (curcuminoids: curcumin, demethoxycurcumin and bis-demethoxycurcumin) exert an anticancer role in different cancer models such as breast cancer, colon adenocarcinoma, prostate cancer, by regulating multiple intracellular signaling pathways involving proliferation, apoptosis, cell phase-related genes, cell migration, invasion and metastasis, immune system, microRNAs, and telomerase activity [5].

In human, various clinical studies have been performed, demonstrating that Curcuma longa or curcumin were able to improve clinical, pathological or serum markers in colon, prostate, breast, skin cancer, vulva, oral cavity, chronic myeloid leukemia and pancreatic cancer. Likewise, curcumin was shown to improve side effects or sensitize tumors to treatment with radiotherapy and chemotherapy [6].

In the present work, we observe that turmeric increased the survival of mice with cancer, however, in other parameters statistically analysis gave similar results as the control group. Curcuma therapeutic failure could be explained by its low bioavailability. Unformulated and unprocessed curcuma or curcumin are highly insoluble in water, and is known for its poor gastrointestinal absorption and bioavailability. Curcumin when consumed orally undergoes rapid conjugation in the small bowel, undergoing rapid excretion in the urine and feces. Various approaches have been used to overcome curcumin poor absorption, rapid metabolism and poor bioavailability, including micelles and liposomes formulations or by interaction with macromolecules such as gelatin, and various polysaccharides [21].

We gave curcuma in a solid diet containing coconut milk, egg yolk and corn starch, which should have increased bioavailability, in fact $52 \%$ of the treated mice showed a profile similar to Pepper and Turppep groups, indicating satisfactory treatment response reflected in smaller tumors and greater survival (see figures 1 and 2). These results would suggest that turmeric bioavailability is a variable phenomenon, related either to polymorphisms of the enzymes involved in their metabolism [21].

In the present paper, we observe that pepper increased the pre-patent period for cancer development, decreased the evolution of the volume of the primary tumor, decreased metastases number and increased survival.

The main component with anticancer activity contained in Piper nigrum is piperine. Surprisingly, although there are abundant in vitro and in vivo studies on the antineoplastic mechanism of piperine [8], few studies $(\mathrm{n}=4)$ have been conducted on the effect of this substance on the evolution of cancer in animal models. There are no studies on the specific effect of Piper nigrum extracts in experimental animals, only Piper longum extracts have been tested.

Lai et al (2012) [22] reported that piperine inhibited the growth of 4T1 breast cancer cells in a dose and time-dependent manner, decreasing tumor development and metastasis. Samykutty et al (2013) [23] showed that piperine markedly decreases prostate tumor growth in athymic nude mice model. Pradeep and Kuttan (2002) [24] revealed that piperine is an anti-metastatic agent in C57BL/6 mice transplanted with B16F-10 melanoma. Bezerra et al (2008) [25] disclosed that piperine inhibited solid tumor development in mice transplanted with Sarcoma 180 cells. On the other hand, Sunila and Kuttan (2004) [14], demonstrated that alcoholic extracts of Piper longum inhibited Dalton's lymphoma development and increased survival in mice transplanted with ascites cells of Ehrlich's carcinoma.

Therefore, the works described above together with our data, indicate that Piper nigrum through piperine has a chemopreventive anti-cancer activity. Although, Piper nigrum showed anti-cancer activity by itself, its effect was enhanced by combining it with turmeric. 
The potentiation can be visualized by stating Piper nigrum favored anti-cancer Curcuma longa activity by increasing its bioavailability. Piperine is regarded as the world' first scientifically validated bioavailability enhancer. To explain bioenhancer piperine activity, different enzymatic inhibition mechanisms of drug first-pass elimination have been postulated [26].

However, the potentiation observed can not only be due to the inhibitory effect that Piper nigrum would have on the catabolism of curcumin, but it could be due to a synergistic effect related to the activation of various effector signaling pathways at the molecular level. For instance, triggering cell cycle arrest and cancer cells apoptosis [27]. In addition to the effects related to cell cycle inhibition and caspases activation, curcumin increases pro-apoptotic proteins, thereby enhancing apoptosis in cancer cells [6].

Curcumin and piperine complement each other favoring anti-metastatic effect. Piperine exerts its effect through MMP3 and MMP-9 inhibition [22], while curcumin inhibits metastases by reducing the expression of CXCL1 and CXCL2 [28]. Likewise, both piperine and curcumin inhibit VEGF expression, which leads angiogenesis inhibition of $[29,30]$. In the present paper, the complement anti-metastatic effect of turmeric and pepper were verified demonstrating that total metastasis and the probability to show pulmonary metastases were less in Pepper and Turpepp group, respectively, as compared with the Control group, disclosing that piperine contained in Pepper, could be the main element preventing metastases.

In the present paper, impaired nociceptive response, in both healthy and tumor bearing paw, for Control, Turmeric and Pepper were demonstrated; on the contrary, mice belonging to Turpepp group preserved nociceptive response at the healthy paw. These results are puzzling, since the development of cancerous tumors has been frequently associated with inflammatory and neuropathic pain, especially in advanced stages of the disease. However, peripheral nervous system is frequently involved in patients with cancer; destruction of dorsal root ganglion cells (DRGC) due to lymphocytic infiltración, mediate a classic syndrome of subacute sensory neuronopathy [31], which manifests as severe sensory loss with marked sensory ataxia and severe proprioception impairment [32]. DRGC express neurotrophic factor, chemokine, toll-like and tumor necrosis factor receptors, which can modulate sensorial function o neuronal survival [33]. In fact, melanoma tumors are frequently painless, indicating that DRGC networks are remodeled. In our animal model, loss of sensitivity could be associated to DRGC destruction or remodeling by chemokines or cytokines signals; while conserved nociception response in healthy paw of Turppep group could reflect antimelanoma or antiinflammatory cell action of spices, that avoid DRGC trophic negative effects or protects again DRGC infiltration and damage.

On the elevated plus maze Turppep mice displayed increased locomotor activity, that could reflects a better animal wellbeing as consequence of the effectiveness of the diet combination on cancer progression. Depressive like behavior in mice suffering cancer it has been broadly demonstrated, and related to inflammatory mediators, especially to systemic IL-6 [34]. On the other hand, it has been reported curcumin had antidepressant-like effects that involve the central monoaminergic neurotransmitter systems [35]. Similarly, co-administration of curcumin with piperine potentiated curcumin antidepressant effect on LPS induce-anxiety and depressive-like behavior [36]. Because, inflammations are related to depression, curcumin and piperine anti-inflammatory effects could also be responsible of their anti-depressive effect.

We observed that mice from control group, bearing bigger tumors (more than $500 \mathrm{mg}$ ), the quantity of weight loss was directly associated with the weight of the tumor. On the contrary, in the experimental groups, the smaller the tumor, the greater the weight loss. Weight loss during cancer evolution is related to cancer cachexia, a multifactorial chronic wasting syndrome that involves skeletal muscle and adipose tissue loss. A number of pro-inflammatory cytokines, but particularly, TNF- $\alpha$ have direct catabolic effects on skeletal muscle. On the other hand, the role of TNF- $\alpha$ on cancer progression is controversial, its effects depend on its tissue levels; at low concentrations sustain cancer development, while at high concentrations has anti-tumor effect. These outputs could be related with inflammation-induce cell proliferation or an apoptosis phenomenon, respectively. TNF receptors are death receptors that activate either apoptosis via caspase 8 pathway or cell proliferation via activation of NF-k $\beta$, depending on the intra and extracellular environments. Inflammation favor TNF alpha induce cell proliferation because inflammation pathways converge in NF$\mathrm{k} \beta$, increasing its expression and potentiating its effect. Piperine and curcumin are anti-inflammatory substances that inhibit NF-k $\beta$ signaling pathways and activated apoptosis pathways, therefore acting on cancer cells could decrease cell proliferation and induce apoptosis. Both compounds also induce weight loss by favoring TNF $\alpha$ effects on energy metabolism. This reasoning could explain why the groups treated with turmeric and pepper lost weight was associated with a decreased tumor development and increased survival [37, 38]. 
In the present paper weight loss was positively correlated with tumor size in Control group, which in turn was associated with a decrease in thymus weight and an increase in spleen weight. Thymic involution has been previously described in malignant tumors bearing mice, where a profound depletion of CD4+ and CD8+ cells in peripheral blood was observed due to an increased apoptosis and block in T cell maturation and it is responsible of tumor-induced immunosuppression [39]. Thymus involution and spleen enlargement has been previously found in B-16 C57BL bearing mice, being related to a different lymphocytes redistribution and traffic induced by tumor burden [40]. On the contrary, weight loss was negatively associated with tumor size and associated with thymus hyperplasia in pepper group, phenomena that should be associated by strong antitumor T cell immune response. In this sense, curcumin and piperine inhibited apoptosis of thymus cells induced by pyrethroid insecticide [41].

Here, Turmeric and Pepper groups had increased activity of adenosine deaminase, which breakdown adenosine to inosine. Adenosine is an immunosuppressive metabolite produced by the tumor to promote growth, invasion, metastasis, and immune evasion; decreased levels of adenosine favor Th1 response [42] supporting antitumor activity. Unexpectedly, Turpepp group did not show adenosine deaminase increase; therefore, we can speculate ADA expression is a complex phenomenon depending on the trophic environment of the immune cells.

Finally, we observe pepper had more potency than curcuma extracts on cell anaerobic metabolism and MTT viability, certainly explained by the degree of purity of the spices used and by the cellular bioavailability. The greatest potency of pepper in MTT as compared with anaerobic assay could be related to cytotoxic effect. Formazan are generated mainly in mitochondria by NAD(P)H-dependent cellular oxidoreductase enzymes in cells with conserved integrity and function, while anaerobic metabolism can be displayed not only by integral cells but also by exosomes released in response to cell aggression or during apoptosis $[43,44]$.

\section{Conclusion}

In conclusion, in this work we demonstrate that Piper nigrum showed an antineoplastic chemopreventive activity in the B16F10 malignant melanoma, which was enhanced by the antineoplastic chemopreventive synergistic effect of Curcuma longa. The preventive effect is based on avoiding the carcinogenesis process and the synergistic effect could be due to a complementary effect in the activation of various effector-signaling pathways at the molecular level, which counteract carcinogenesis and boost cancer immunogenicity and immunosurveillance. Posing, that the combination of the extracts of both plants and their principles could be very useful in the prevention or treatment of malignant melanoma.

\section{Compliance with ethical standards}

\section{Acknowledgments}

Pérez-Pérez AI (Email: aisap1999@gamil.com) belongs to the Biochemistry Unit Youth Scientific Talent Program supported by The Council for Scientific, Humanistic and Technological Development (CDCHT), "Lisandro Alvarado" Center West University (Barquisimeto, Venezuela).

\section{Disclosure of conflict of interest}

The authors report that there is no conflict of interest regarding the publication of this paper.

\section{Statement of ethical approval}

All experimental procedures performed were based in "The Bioethics and Biosafety Manual" of the National Fun for Science and Technology, Ministry of Popular Power for Science and Technology, Venezuela. The project was approved and supervised by Bioethics Committee at the Department of Functional Sciences, School of Health Sciences, Universidad Centrooccidental "Lisandro Alvarado".

\section{References}

[1] Balch CM, Gershenwald JE, Soong SJ, Thompson JF, Atkins MB, Byrd DR, et al. Final version of 2009 AJCC melanoma staging and classification. J Clin Oncol. 2009; 27 (36): 6199-6206.

[2] McGuire S. World Cancer Report 2014. Geneva, Switzerland: World Health Organization, International Agency for Research on Cancer, WHO Press, 2015. Adv Nutr. 2016; 7 (2): 418-419. 
[3] Kooti W, Servatyari K, Behzadifar M, Asadi-Samani M, Sadeghi F, Nouri B, et al. Effective medicinal plant in cancer treatment, part 2: review study. J Evid Based Complementary Altern Med. 2017; 22 (4): 982-995.

[4] Zhou Y, Zheng J, Li Y, Xu D, Li S, Chen Y, et al. Natural Polyphenols for Prevention and Treatment of Cancer. Nutrients. 2016; 8 (8): 515.

[5] Aggarwal BB, Yuan W, Li S, Gupta SC. Curcumin-free turmeric exhibits anti-inflammatory and anticancer activities: identification of novel components of turmeric. Mol Nutr Food Res. 2013; 57 (9): 1529-1542.

[6] Unlu A, Nayir E, Kalenderoglu MD, Kirca O, Ozdogan M. Curcumin (Turmeric) and cancer. J BUON. 2016; 21 (5):1050-1060.

[7] Prashant A, Rangaswamy C, Yadav AK, Reddy V, Sowmya MN, Madhunapantula S. In vitro anticancer activity of ethanolic extracts of Piper nigrum against colorectal carcinoma cell lines. Int J of Appl and Basic Med Res. 2017; 7 (1): 67-72.

[8] Stojanović-Radić Z, Pejčić M, Dimitrijević M, Aleksić AV, Anil Kumar N, Salehi BC, et al. Piperine-A Major Principle of Black Pepper: A Review of Its Bioactivity and Studies. Appl. Sci. 2019; 9 (20): 4270.

[9] Fofaria NM, Kim SH, Srivastava SK. Piperine causes G1 phase cell cycle arrest and apoptosis in melanoma cells through checkpoint kinase-1 activation. PLoS One. 2014; 9 (5): e94298.

[10] Bhardwaj RK, Glaeser H, Becquemont L, Klotz U, Gupta SK, Fromm MF. Piperine, a major constituent of black pepper, inhibits human P-glycoprotein and CYP3A4. J Pharmacol and Exp Ther. 2002; 302 (2): 645-650.

[11] Shoba G, Joy D, Joseph T, Majeed M, Rajendran R, Srinivas PS. Influence of piperine on the pharmacokinetics of curcumin in animals and human volunteers. Planta Med. 1998; 64 (4): 353-356.

[12] Mittal R, Gupta RL. In vitro antioxidant activity of piperine. Methods Find Exp Clin Pharmacol. 2000; 22 (5): 271274.

[13] Srinivasan K. Black pepper and its pungent principle-piperine: a review of diverse physiological effects. Crit Rev Food Sci Nutr. 2007; 47 (8): 735-748.

[14] Sunila ES, Kuttan G. Immunomodulatory and antitumor activity of Piper longum Linn and piperine. J Ethnopharmacol. 2004; 90 (2-3): 339-346.

[15] Santos J, Brito M, Ferreira R, Moura AP, Sousa T, Batista T, et al. Th1-Biased immunomodulation and in vivo antitumor effect of a novel piperine analogue. Int J Mol Sci. 2018; 19 (9): 2594.

[16] Manayi A, Nabavi SM, Setzer WN, Jafari S. Piperine as a Potential Anti-cancer Agent: A Review on Preclinical Studies. Curr Med Chem. 2018; 25 (37): 4918-4928.

[17] Park W, Amin AR, Chen ZG, Shin DM. New perspectives of curcumin in cancer prevention. Cancer Prev Res (Phila). 2013; 6 (5): 387-400.

[18] Huang MT. Antioxidant and antitumorigenic properties of curcumin. In Food Factors for Cancer Prevention. Tokyo, Springer. 1997.

[19] Menon VP, Sudheer AR. Antioxidant and anti-inflammatory properties of curcumin. Adv Exp Med Biol. 2007; 595: 105-125.

[20] Bose S, Panda AK, Mukherjee S, Sa G. Curcumin and tumor immune-editing: resurrecting the immune system. Cell Div. 2015; 10 (1): 1-13.

[21] Stohs SJ, Chen C, Preuss HG, Ray SD, Bucci LR, Ji J, et al. The fallacy of enzymatic hydrolysis for the determination of bioactive curcumin in plasma samples as an indication of bioavailability: a comparative study. BMC complementary and alternative medicine. 2019; 19 (1): 293-301.

[22] Lai LH, Fu QH, Liu Y, Jiang K, Guo QM, Chen QY, et al. Piperine suppresses tumor growth and metastasis in vitro and in vivo in a 4T1 murine breast cancer model. Acta Pharmacol Sin. 2012; 33 (4): 523-530.

[23] Samykutty A, Shetty AV, Dakshinamoorthy G, Bartik MM, Johnson GL, Webb B, et al. Piperine, a bioactive component of pepper spice exerts therapeutic effects on androgen dependent and androgen independent prostate cancer cells. PLoS One. 2013; 8 (6): e65889.

[24] Pradeep CR, Kuttan G. Effect of piperine on the inhibition of lung metastasis induced B16F-10 melanoma cells in mice. Clin Exp Metastasis. 2002; 19 (8): 703-708. 
[25] Bezerra DP, de Castro FO, Alves AP, Pessoa C, Moraes MO, Silveira ER, et al. In vitro and in vivo antitumor effect of 5-FU combined with piplartine and piperine. J Appl Toxicol. 2008; 28 (2): 156-163.

[26] Atal N, Bedi KL. Bioenhancers: revolutionary concept to market. J Ayurveda and Integr Med. 2010 ; 1 (2): $96-99$.

[27] Rather RA, Bhagat M. Cancer chemoprevention and piperine: Molecular mechanisms and therapeutic opportunities. Front Cell Dev Biol. 2018; 6: 10-22.

[28] Killian PH, Kronski E, Michalik KM, Barbieri O, Astigiano S, Sommerhoff CP, et al. Curcumin inhibits prostate cancer metastasis in vivo by targeting the inflammatory cytokines CXCL1 and -2. Carcinogenesis. $2012 ; 33$ (12): 2507-2519.

[29] Sunila ES, Kuttan G. Piper longum inhibits VEGF and proinflammatory cytokines and tumor-induced angiogenesis in C57BL/6 mice. Int Immunopharmacol. 2006; 6 (5): 733-741.

[30] Lin SS, Lai KC, Hsu SC, Yang JS, Kuo CL, Lin JP, et al. Curcumin inhibits the migration and invasion of human A549 lung cancer cells through the inhibition of matrix metalloproteinase-2 and -9 and Vascular Endothelial Growth Factor (VEGF). Cancer Lett. 2009; 285 (2): 127-133.

[31] Koike H, Sobue G. Paraneoplastic neuropathy. Handb Clin Neurol. 2013; 115: 713-726.

[32] Muppidi S, Vernino S. Paraneoplastic neuropathies. Continuum (Minneap Minn). 2014; 20 (5): 1359-1372.

[33] Keskinov AA, Tapias V, Watkins SC, Ma Y, Shurin MR, Shurin GV. Impact of the sensory neurons on melanoma growth in vivo. PLoS One. 2016; 11 (5): e0156095.

[34] Lamkin DM, Lutgendorf SK, Lubaroff D, Sood AK, Beltz TG, Johnson AK. Cancer induces inflammation and depressive-like behavior in the mouse: Modulation by social housing. Brain Behav Immun. 2011 ; 25 (3): $555-$ 564 .

[35] Xu Y, Ku BS, Yao HY, Lin YH, Ma X, Zhang YH, et al. The effects of curcumin on depressive-like behaviors in mice. Eur J Pharmacol. 2005; 518 (1): 40-46.

[36] Jangra A, Kwatra M, Singh T, Pant R, Kushwah P, Sharma Y, et al. Piperine augments the protective effect of curcumin against lipopolysaccharide-induced neurobehavioral and neurochemical deficits in mice. Inflammation. 2016; 39 (3): 1025-1038.

[37] Patel HJ, Patel BM. TNF- $\alpha$ and cancer cachexia: Molecular insights and clinical implications. Life Sciences. 2017; 170: $56-63$.

[38] Montfort A, Colacios C, Levade T, Andrieu-Abadie N, Meyer N, Ségui B. Les anticorps anti-TNF $\alpha$ dans l'immunothérapie du mélanome [Anti-TNF $\alpha$ antibodies in melanoma immunotherapy]. Med Sci (Paris). $2018 ; 34$ (10): 788-791.

[39] Sun S, Ji H, Feng Y, Kang Y, Yu J, Liu A. A novel mechanism of tumor-induced thymic atrophy in mice bearing H22 hepatocellular carcinoma. Cancer Manag Res. 2018; 10: 417-424.

[40] Shohat B, Agam G, Brosh S, Sperling O, Sharon N. Adenosine deaminase activity in lymphocyte subpopulations of B-16 melanoma and normal C57BL bearing mice. Immunol Lett. 1984; 8 (6): 307-310.

[41] Kumar A, Sasmal D, Sharma N. Mechanism of deltamethrin induced thymic and splenic toxicity in mice and its protection by piperine and curcumin: in vivo study. Drug Chem Toxicol. 2018; 41 (1): 33-41.

[42] Csóka B, Himer L, Selmeczy Z, Vizi ES, Pacher P, Ledent C, et al. Adenosine A2A receptor activation inhibits T helper 1 and T helper 2 cell development and effector function. FASEB J. 2008; 22 (10): 3491-3499.

[43] Surin AM, Sharipov RR, Krasil'nikova IA, Boyarkin DP, Lisina OY, Gorbacheva LR, et al. Disruption of Functional Activity of Mitochondria during MTT Assay of Viability of Cultured Neurons. Biochemistry (Mosc). 2017 ; 82 (6): 737-749.

[44] Göran-Ronquist K. Extracellular vesicles and energy metabolism. Clin Chim Acta. 2019; 488: $116-121$. 